American Journal of Economics and Business Administration 3 (2): 370-376, 2011

ISSN 1945-5488

(C) 2010 Science Publications

\title{
Analyzing Accuracy and Accessibility in Information and Communication Technology Ethical Scenario Context
}

\author{
${ }^{1}$ Maslin Masrom, ${ }^{2}$ Zuraini Ismail, ${ }^{1}$ Rashidah Nural Anuar, \\ ${ }^{3}$ Ramlah Hussein and ${ }^{3}$ Norshidah Mohamed \\ ${ }^{1}$ Razak School of Engineering and Advanced Technology, \\ University Technology Malaysia, Kuala Lumpur, Malaysia \\ ${ }^{2}$ Advanced Informatics School, University Technology Malaysia, \\ Kuala Lumpur, Malaysia \\ ${ }^{3}$ Kulliyyah of Information and Communication Technology, \\ International Islamic University Malaysia, Selangor, Malaysia
}

\begin{abstract}
Problem statement: Recently, the development of Information and Communication Technology (ICT) is indispensable to life. The utilization of ICT has provided advantages for people, organizations and society as a whole. Nevertheless, the widespread and rapid use of ICT in society has exacerbated existing ethical issues or dilemmas and also led to the emergence of new ethical issues such as unauthorized access, software piracy, internet pornography, privacy protection, information gap and many others. Approach: Therefore, the aim of this study is to discuss several issues of the ICT ethics. It will focusing on two major issues, that is, data accuracy and accessibility. Results: The results indicated that more than half percentage of respondents tend to be ethical in data accuracy scenario and also in accessibility scenario. Several computer ethics scenarios that relate to the data accuracy and accessibility are presented and the results of analysis are then discussed. Conclusion: Based on the results in this study, computer ethics issues such as data accuracy and accessibility should receive more attention in the ICT field.
\end{abstract}

Key words: Computer ethics, analyzing accuracy, accessibility, ICT ethical scenario, data accuracy

\section{INTRODUCTION}

The misuse of computer and Information and Communication Technology (ICT) and unethical behavior towards ICT has caused significant losses to society and business (Leonard and Cronan, 2005). It continues to be one of the major problems in the current age. Computer Ethics is a branch of practical philosophy which deals with how computing professionals should make decisions regarding professional and social conduct.

The term "computer ethics" was first coined by Maner $(1980 ; 1996)$ in the mid-1970s, but only since the 1990s has it started being integrated into professional development programs in academic settings. The conceptual foundations of computer ethics are investigated by information ethics, a branch of philosophical ethics established by Floridi. Computer ethics is an important topic in computer applications.
Information ethics is the field that investigates the ethical issues arising from the development and application of information technologies. It provides a critical framework for considering moral issues concerning informational privacy, moral agency (for example, whether artificial agents may be moral), new environmental issues (especially how agents should one behave in the infosphere), problems arising from the life-cycle (creation, collection, recording, distribution, processing and others) of information (especially ownership and copyright, digital divide). Information Ethics is related to the fields of computer ethics (Tucker, 1991) and the philosophy of information.

Ethical issue or dilemma is a situation that will often involve an apparent conflict between moral imperatives, in which to obey one would result in transgressing another. It is regarding the life of information are becoming increasingly important in a society that is defined as "the information society".

Corresponding Author: Maslin Masrom, Razak School of Engineering and Advanced Technology, University Technology Malaysia, Kuala Lumpur, Malaysia 
Information transmission and literacy are essential concerns in establishing an ethical foundation that promotes fair, equitable and responsible practices. Information ethics broadly examines issues related to ownership, access, privacy, security and community. Information technology affects fundamental rights involving copyright protection, intellectual freedom, accountability and security. According to (Tucker, 1991), Computing Curriculum report, Association of Computing Machinery, in conjunction with the Institute of Electrical and Electronic Engineers, identified the importance of including a "social and professional context" as part of the core curriculum for all computer science majors. This report highlights the need of students to understand the basic cultural, social, legal and ethical issues inherent in the discipline of computing.

The study is organized as follows. This study begins with the introduction of the study. It continues with a literature review and follows by research methodology and results. Finally the conclusion of the study is presented.

Literature review: Computers have become an integral part of our society. Consequently, both use and misuse of computers have increased dramatically. Although proper use has proven to be beneficial to businesses and professionals, abuse has caused significant losses to businesses society. Thus, certain guide lines for safe and ethical use are needed (Mahmoud et al., 2006).

What is computer ethics: Ethics is about guiding decision-making between alternatives involving the actions of people, helping to answer questions as to what the individual and society ought to do. In short, ethics is about making judgments about good and evil, or right or wrong.

Computer ethics, sometimes called ICT ethics is the ethical concepts that define a moral ICT domain or area, are those that define any other domain of human activity. According to Deborah Johnson, computer ethics is the analysis of the nature and social impact of computer technology and the corresponding formulation and justification of policies for the ethical use of such a technology. The number and types of application of computing has felt around the world.

The BBC English Dictionary defines ethics as "moral beliefs and rules about right and wrong". Ethics can also be defined as "the rules of conduct recognized in respect to a particular class of human actions" (Sinclair, 1993).

Computer ethics issues: The advancement of more complex ICT tools and computers is not solely a technological issue. It has effects in a variety of areas ranging from ethical to social and also legal. Besides the benefits brought by the advancement of the technologies, problems also are arising.

In this respect, the computer or ICT use has generated ethical issues that would have been impossible without computer and ICT. And also, the lack of non-computer analogies for moral issues regarding computer supports the uniqueness of computer ethics. There is much debate about ICT in relation to the two areas: Information accuracy and access to information.

Computer ethics issues can be classified using the traditional concepts of privacy, property, crime and abuse, power and responsibility, professional practice, accountability and liability (Myers and Miller, 1996). The major ethical issues that emerge from these various sources include; codes of ethics, data accuracy and accessibility. In this study, the authors used "ICT ethics" as the term for the study.

Accuracy: Accuracy represents the legitimacy, precision and authenticity with which information is rendered. Because of the pervasiveness of information about individuals and organizations contained in information systems, special care must be taken to guard against errors and to correct known mistakes. Difficult questions remain when inaccurate information is shared between computer systems (Ellis and Griffith, 2001). According to (Straub and Nance, 1990), the legal liability issues associated with information. Who is held accountable for the errors? Which party is liable for inexact or incorrect information that leads to devastation of another?

Accessibility: Accessibility deals with the right or privilege to obtain data or information from another source. What information does one have a right to obtain from government or business organization computer systems? What data or information does an organization own? (Ellis and Griffith, 2001). The idea of access is very broad and general today. The term has evolved with its meaning. Access meant being connected to the World Wide Web. In 1999, its meaning is multifaceted (Baker et al., 2002).

Computer ethics scenario: Scenarios consist of a description of a situation and resulting action. It is widely used by organizations to understand different ways that future events might unfold.

Scenarios related to the field of computing were first illustrated by John Parker, who conducted a workshop attended by a diverse group of professionals, 
including computer scientists, psychologists, sociologist and lawyers. Scenarios are commonly used to examine ethical judgments and intentions in many different areas, including Information System (IS) (WIPO, 2007).

Computer ethics scenario or ethical scenarios or case study is a short narrative of one or more events that involve one or more ethical issue (WIPO, 2007). Basically, with those scenarios, the person involves in the study or evaluation process is expected to analyze the participants' actions and arrive at a judgment concerning their ethical nature.

Ethical issues have been presented by researchers in the past via scenarios or short statements (Brey, 2000). Sometimes, scenarios in the form of statements were chosen to obtain a larger range of issues. According to Alpert, the length of the scenarios does not allow for more than a few ethical situations and the specific content endemic to ethical scenarios limit the generalizations that can be made. Short statements are considered to have less bias than longer statements. Examples of scenarios written in short statements are illustrated in Table 1.

Accuracy scenario: Misinformation has a way of fouling up people's lives, especially when the party with the inaccurate information has an advantage in power and authority. Below is a scenario related to the accuracy issue (Mason, 1986).

Consider the plight of one Louis Marches. Marches, an immigrant, was a hard working man who, with his wife Eileen, finally saved enough money to purchase a home in Los Angeles during the 1990s. They took out a long term loan from Crocker National Bank. Every month Louis Marches would walk to his neighborhood bank, loan coupon book in hand, to make his payment of \$195.53. He always checked with care to insured that the teller had stamped "paid" in his book on the proper line just opposite the month for which the payment was due. And he continued to do his long after the bank converted to its automated loan processing system.

One September a few years ago Marches was notified by the bank that he had failed to make his current house payment. Marches grabbed his coupon book, marched to the bank and in broken English that showed traces of his old country heritage, tried to plain to the teller that this dunning notice was wrong. He had made his payment he claimed. The stamp on his coupon book proved that he had paid. The teller punched Marches' loan number on the keyboard and reviewed the confirm Marches' claim, nor subsequently could the head teller, nor the branch manager. When faced with a computer generated screen that clearly showed that his account was delinquent, this hierarchy of bankers simply ignored the entries recorded in his coupon book and also his attendant raving. Confused, Marches left the bank in disgust.

In October, however, Marches dutifully went to the bank to make his next payment. He was told that he could not make his October payment because he was one month in arrears. He again showed the teller his stamped coupon book. She refused to accept it and he stormed out of the bank.

Table 1: Scenario statements

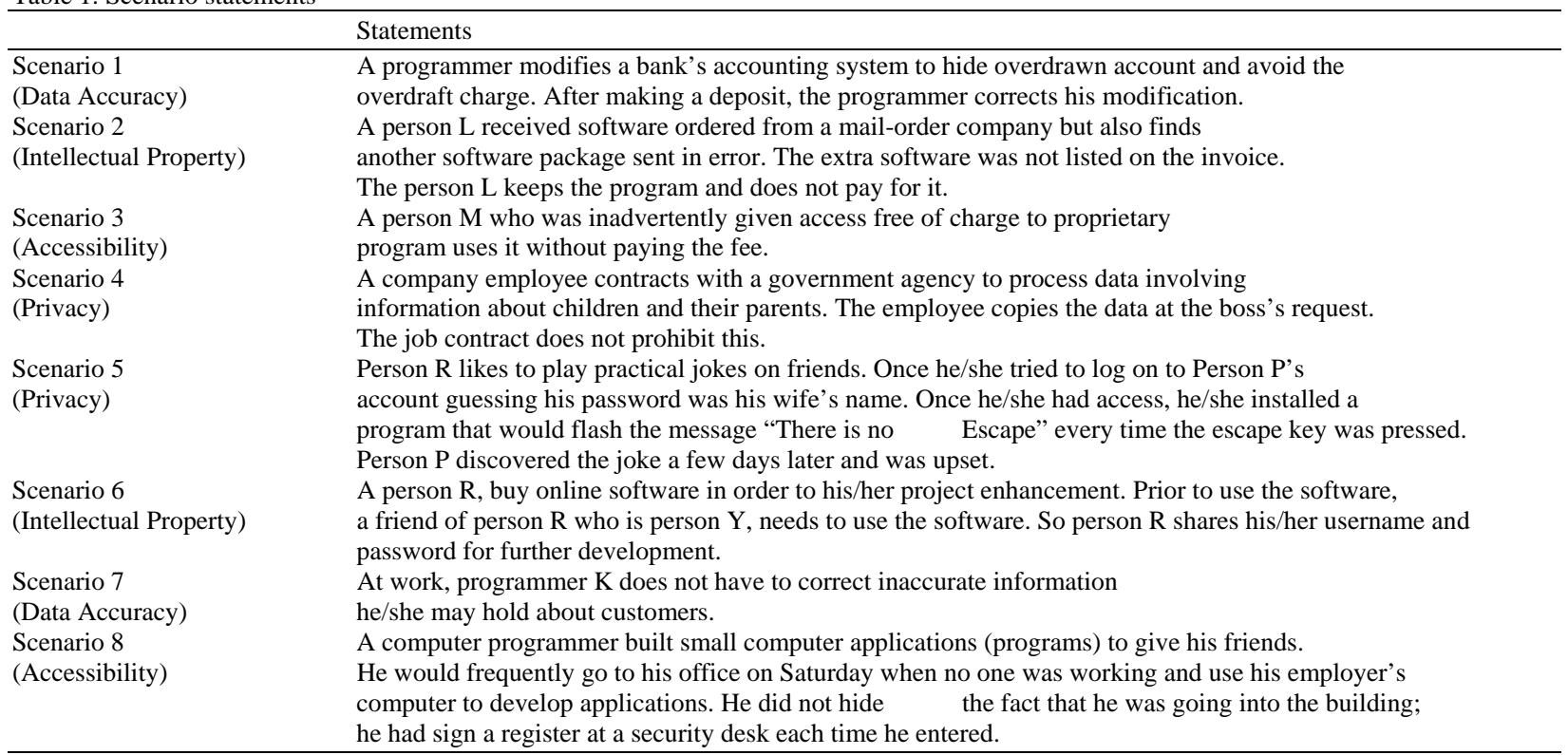


In November he returned on schedule as he had done for over 20 years and tried to make his payment again, only to be told that he was now two months in arrears. And so it went until inevitably the bank foreclosed. Eileen learned of the foreclosure from an overzealous bank debt collector while she was in bed recovering from a heart attack. She collapsed upon hearing the news and suffered a near fatal stroke which paralyzed her right side. Sometime during this melee Marches, who until this time had done his own legal study, was introduced to an attorney who agreed to defend him. They sued the bank. Ultimately, after months of anguish, the Marches received a settlement for \$268, 000. All that the bank official who testified could say was, "Computers make mistakes. Banks make mistakes, too."

Accessibility scenario: According to (Mason, 1986), the avenue to information is through literacy. Each innovation in information handling, from the invention of study to the modern computer, has placed new demands on achieving literacy. In an information society a citizen must possess at least three things to be literate:

- One must have the intellectual skills to deal with information. These are skills such as reading, writing, reasoning and calculating. This is a task for education

- One must have access to the information technologies which store, convey and process information. This includes libraries, radios, televisions, telephones and increasingly, personal computers or terminals linked via networks to mainframes. This is a problem in social economics

- Finally, one must have access to the information itself. This requirement returns to the issue of property and is also a problem in social economics

Some other scenarios related to this accessibility issue are shown below (Ellis and Griffith, 2001):

- The information security manager in a large company was also the access control administrator of a large electronic mail system operated for company business among its employees. The security manager routinely monitored the contents of electronic correspondence among employees. He discovered that a number of employees were using the system for personal purposes; the correspondence included love letters, disagreement between married partners, plans for homosexual relations and a football betting pool. The security manager routinely informed the human resources department director and the corporate security officer about the communications and gave them printed listings of them. In some cases, managers punished employees on the basis of the contents of these electronic mail messages. Employees objected to the monitoring of their electronic mail, claiming that they had the same right of privacy as they had using the company's telephone system or internal study inter-office mail system

- A popular Internet service provider offers on-line registration. Any user with a modem can dial the Home link Network and register for Internet service from their computer. What the users do not know is that as part of registration, Home link scans their hard drive assessing their system for potential new software marketing opportunities

The scenario represented in Table 1 is found related to scenarios of Malaysian context which is divided to four issues; Privacy, Data Accuracy, Intellectual Property and Accessibility.

\section{MATERIALS AND METHODS}

This part presents and describes the instrument and pilot study conducted for this project.

Instrument: The instrument of the study, namely, questionnaire was structured based on the goal. The aim of this questionnaire is to analyze students' perception on IT ethical issues in Malaysian higher education environment. The questionnaire was divided into two parts. The first part seeks the profile of respondent, while second part comprises of eight IT-related scenarios. For each scenario, there are nine measures to which respondents need to give their opinions. The questionnaire was personally administrated. The advantage of personally administrated questionnaire is we are able to collect data within a short time.

Pilot study: The aim of conducting this pilot study is to get feedback from respondents regarding the developed instrument before starting on the actual survey. The questionnaires were distributed to 100 computer science undergraduate students at University Technology Malaysia (UTM) International Campus. It was found no major changes were required on the questionnaire's layout or wordings. A response rate of $100 \%$ recorded. The returned questionnaires were then analyzed using SPSS 16.0.

\section{RESULTS AND DISCUSSION}

This part will present the results of the study. Table 3 and 5 are represented for data accuracy scenario while Table 4 and 6 are represented for accessibility scenario. 
The survey conducted based on the six questions in the Table 2. Scenarios are commonly used to examine ethical judgments and intentions in many different areas. Consistent with this approach, scenarios developed and were adopted (Table 1). Measures of moral intensity were adapted from prior research, as were items that measured ethical perceptions and intentions (Mason, 1986).

Moral intensity is multidimensional, consisting of six components: (1) magnitude of consequences-the aggregate harm or benefits of the act; (2) social consensus-the degree to which others think the act is good or evil; (3) temporal immediacy-the length of time between the act and its consequences; (4) probability of effect-the likelihood that the act will cause harm or benefits; (5) proximity-the social distance between the decision maker and those affected by the act; (6) concentration of effect-the number of people affected by the act (Table 2) (Mason, 1986).

Table 2: Questions of moral intensity

No. Question

Q1. The overall harm (if any) done as a result of the actor's action would be very small.

Q2. Most people would agree that (the actor's) actions are wrong.

Q3. (The actor's) actions will not cause any harm in the immediate future.

Q4. There is a very small likelihood that (actor's) actions will actually cause any harm.

Q5. If (the actor) is a personal friend of her/his boss, the action is wrong.

Q6. (The actor's) actions will harm very few people (if any).

Table 3: Percentage of respondents for scenario 1

\begin{tabular}{lllllll}
\hline Scale (\%) & Q1 & Q2 & Q3 & Q4 & Q5 & Q6 \\
\hline Agree & 38.1 & 56.6 & 27.1 & 35.3 & 47.5 & 35.4 \\
Neutral & 34.0 & 27.3 & 29.2 & 40.4 & 32.3 & 32.3 \\
Disagree & 27.9 & 16.1 & 43.7 & 24.2 & 20.2 & 32.3 \\
\hline
\end{tabular}

Table 4: Percentage of respondents for scenario 3

\begin{tabular}{lllllll}
\hline Scale (\%) & Q1 & Q2 & Q3 & Q4 & Q5 & Q6 \\
\hline Agree & 37.0 & 28.0 & 28.0 & 39.0 & 40.0 & 33.0 \\
Neutral & 35.0 & 35.0 & 35.0 & 29.0 & 37.0 & 35.0 \\
Disagree & 25.0 & 19.0 & 34.0 & 28.0 & 20.0 & 29.0 \\
\hline
\end{tabular}

Table 5: Percentage of respondents for scenario 7

\begin{tabular}{lllllll}
\hline Scale (\%) & Q1 & Q2 & Q3 & Q4 & Q5 & Q6 \\
\hline Agree & 51.0 & 32.0 & 32.0 & 42.0 & 42.0 & 43.0 \\
Neutral & 38.0 & 30.0 & 27.0 & 29.0 & 28.0 & 29.0 \\
Disagree & 23.0 & 11.0 & 33.0 & 21.0 & 22.0 & 19.0 \\
\hline
\end{tabular}

Table 6: Percentage of respondents for scenario 8

\begin{tabular}{lllllll}
\hline Scale (\%) & Q1 & Q2 & Q3 & Q4 & Q5 & Q6 \\
\hline Agree & 42.0 & 37.0 & 30.0 & 32.0 & 31.0 & 31.0 \\
Neutral & 27.0 & 29.0 & 36.0 & 35.0 & 36.0 & 35.0 \\
Disagree & 21.0 & 24.0 & 23.0 & 23.0 & 23.0 & 24.0 \\
\hline
\end{tabular}

Based on Table 3 and Fig. 1 above, there are responses about the scenario 1; programmer who modifies a bank's account system to hide overdrawn account and avoid the overdraft charge. According to the Q2, more than half respondents indicate (56.6\%) and other questions also showed the percent of respondents indicates agree higher than disagree, except for Q3; which are strongly feel that ethical conduct is important.

As depicted in Table 4 and Fig. 2 above, only Q3 indicate $(28.0 \%)$ which is lower than percent of disagree. For this scenario is all about a person who was inadvertently given access free of charge to a proprietary program uses it without paying the fee (Table 1). The respondents' judgments for the person's action in this scenario, are tending to being ethical when they chose agree which are clearly indicate (37.0\%) for Q1, (28.0\%) for the Q2 and other questions; higher than disagree.

According to Scenario 7 from the Table 5 and Fig. 3 above, the respondents agree to all the questions given except Q3 which is the respondents disagree are more (1\%) than percent of agree. Q1 showed highest percent; more than half respondents indicate $(51.0 \%)$ to agree. This showed that most of the respondents strongly inclined to be ethical in this scenario.

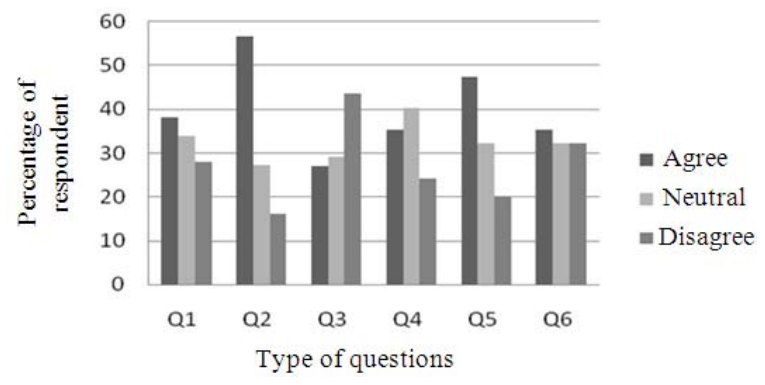

Fig. 1: Percentage of respondents for scenario 1

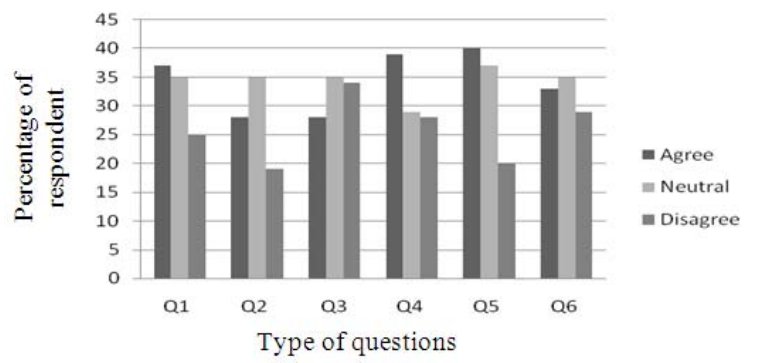

Fig. 2: Percentage of respondents for scenario 3 
Am. J. of Economics and Business Administration 3 (2): 370-376, 2011

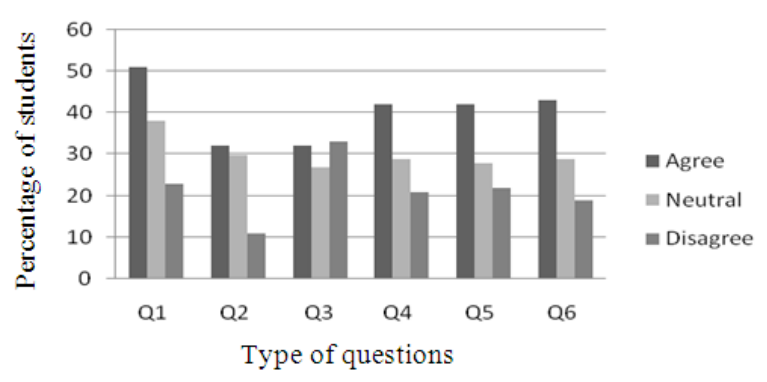

Fig. 3: Percentage of respondent for scenario 7

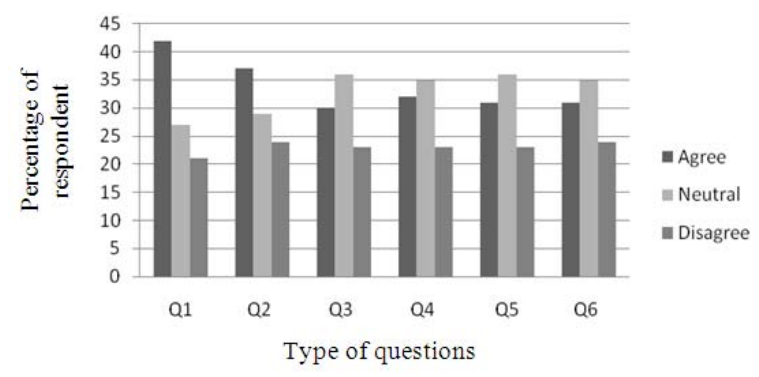

Fig. 4: Percentage of respondents for scenario 8

Scenario 8 discussed about a programmer who built up a small application without others know but he/she did not hide the fact of his/her action (Table 1). Referring to Table 6 and Fig. 4, most of respondent tended to choose neutral which are Q3 to Q6 indicate highest percentage; (36.0\%), (35.0\%), (36.0\%) and $(35.0 \%)$, respectively. However the percentages of respondents chose agree is higher than disagree especially for the Q1, (42.0\%). Again, the respondents still have ethical perception regarding to this scenario.

\section{CONCLUSION}

Computer ethics issues such as data accuracy and accessibility should receive more attention in the ICT field. The pervasive nature of ICT has conceivably made more people, society and organizations aware of the relevant ICT issues. In this study, the results indicate that there are more than half of respondents are aware about the misuse and abuse of computer pertaining to all four scenarios regarding accuracy and accessibility. In fact, they also do not even know about computer ethics by looking at the analysis of respondents who are chosen neutral responses which are contributed higher percentage than unethical behavior. In this respect, Ellis and Griffith (2001) stated that the significance of understanding IT ethical issues is due to their potential in the business arena for significant security and productivity losses. Thus, in order to improve computer ethics or ICT ethics, an overlooked and potentially effective deterrent is the identification of unique and situational characteristics of IS or IT personnel who act ethically or unethically (Ellis and Griffith, 2001). This identification then could lead to the formulation of more effective ways of solving the problem of unethical use of ICT. Thorough efforts should be undertaken to determine how best to address the ethical issues and its' shortfall that will occur in the organizational environment. This results also show that knowledge management community need to consider these ethical issues of ICT as they are related to socio-economic, technical and legalistic issues raised by knowledge management practices (Land et al., 2007).

\section{ACKNOWLEDGEMENT}

The financial support of research grant from Ministry of Higher Education, Malaysia (Vote: 78378) is gratefully acknowledged and also a sincere thanks to College Science and Technology.

\section{REFERENCES}

Baker, K., A. Craddock and A. Orwig, 2002. An Educator's Guide to Accessibility Issues. Ethical and Policy Issues in Informal Technologies University Illinois. http://ed.uiuc.edu/wp/access2002/index.html

Brey, P., 2000. Disclosive computer ethics. Comput. Soc., 30: 10-16. DOI: 10.1145/572260.572264

Ellis, T.S. and D. Griffith, 2001. The Evaluation of IT Ethical Scenarios Using a Multidimensional Scale. ACM SIGMIS Database, 32: 75-85. DOI: 10.1145/506740.506750

Land, F., U. Amjad and S.-M. Nolas, 2007. The ethics of knowledge management. Int. J. Knowl. Manage., 3: 1-9. DOI: 10.4018/JKM.2007010101

Leonard, L.N.K. and T.P. Cronan, 2005. Attitude toward ethical behavior in computer use: A shifting model. Indus. Manage. Data Syst., 5: 1150-1171. DOI: 10.1108/02635570510633239

Mahmoud, M., G.E. El-Refae and S.F. El-Etter, 2006. A rubber band ethics model for computing and information technology practices. Am. J. Applied Sci., $\quad 3: \quad 1910-1915 . \quad$ DOI: 10.3844/ajassp.2006.1910.1915

Maner, W., 1980. Starter Kit in Computer Ethics, Hyde Park. Helvetia Press and the National Information and Resource Center for Teaching Philosophy, New York. http://plato.stanford.edu/entries/ethicscomputer/ 
Maner, W., 1996. Unique Ethical Problems in Information Technology. In: Terrell Ward Bynum and Simon Rogerson, Global Information Ethics, Opragen Publications, USA., pp: 137-154. http://www.cs.bgsu.edu/maner/ethicomp95/keynote 3.pdf

Mason, R.O., 1986. Four ethical issues of the information age. MIS Q., 10: 5-12. DOI: $10.2307 / 248873$

Myers, M.D. and L. Miller, 1996. Ethical dilemmas in the use of information technology: An aristotelian perspective. Ethics Behav., 6: 153-160. DOI: 10.1207/s15327019eb0602_6
Sinclair, J.M., 1993. BBC English Dictionary. 1st Edn., Harper Collins, London, ISBN-10: 000370940X, pp: 1371.

Straub, D.W. and W.D. Nance, 1990. Discovering and disciplining computer abuse in organization: A field study. MIS Q., 14: 45-60. DOI: $10.2307 / 249307$

Tucker, A., 1991. (Ed.) Computing Curricula 1991: Report of the ACM/IEEE-CS Joint Curriculum Task Force. 1st Edn., ACM Press, New York, ISBN: 0818622202, pp: 154.

WIPO, 2007. World Intellectual Property Organization: An overview. World Intellectual Property Organization, Geneva, ISBN-10: 9280516523, pp: 44. 